\title{
DE LÍDER A PARIA DE LA SALUD GLOBAL: BRASIL COMO LABORATORIO DEL "NEOLIBERALISMO EPIDEMIOLÓGICO" ANTE LA COVID-19
}

\author{
FROM GLOBAL HEALTH LEADER TO PARIAH: \\ BRAZIL AS A LABORATORY FOR "EPIDEMIOLOGICAL \\ NEOLIBERALISM” IN THE FACE OF COVID-19
}

\author{
DE LEADER À PARIA DE LA SANTÉ MONDIALE: \\ LE BRÉSIL EN TANT QUE LABORATOIRE DU \\ «NÉO-LIBÉRALISME ÉPIDÉMIOLOGIQUE» \\ FACE À LA COVID-19
}

\author{
Deisy de Freitas Lima Ventura \\ Universidad de São Paulo (USP) Brasil \\ deisy.ventura@usp.br \\ Flávia Thedim Costa Bueno \\ Fundación Oswaldo Cruz (Fiocruz-RJ), Brasil \\ flaviatcbueno@gmail.com
}

\begin{abstract}
RESUMEN: La estrategia institucional de propagación de la Covid-19 implementada por el gobierno federal brasileño es una expresión radical del neoliberalismo en el campo de la salud, definida como neoliberalismo epidemiológico. Esta promoción de la inmunización masiva por contagio, considerada científicamente equivocada y éticamente inaceptable, se opone de manera frontal a las recomendaciones de la Organización Mundial de la Salud (oms). La renuncia al liderazgo pretérito de Brasil en temas de salud global y de cooperación regional en salud se explica también por el carácter ideológico de su nueva política exterior y a la militarización del Ministerio de la Salud.
\end{abstract}

Palabras clave: Brasil, Covid-19; neoliberalismo; salud global; oмs.

AвSTRACT: The institutional strategy for the spread of Covid-19 implemented by the federal government of Brazil is a radical expression of neoliberalism in the field of health, which may be defined as epidemiological neoliberalism. 
This promotion of mass immunity by contagion, seen as both scientifically mistaken and ethically unacceptable, is directly opposed to the recommendations of the World Health Organization (wHo). The renunciation of Brazil's former leadership on global health issues and regional health cooperation is also explained by the ideological character of its new foreign policy and the militarization of the Ministry of Health.

Keywords: Brazil, Covid-19; neoliberalism; global health; wно.

\section{Traducción de Fionn Petch, CM Idiomas}

Résumé: La stratégie institutionnelle de propagation de la Covid-19 mise en œuvre par le gouvernement fédéral brésilien est une expression radicale du néolibéralisme dans le domaine de la santé, défini comme un néolibéralisme épidémiologique. Cette promotion de l'immunité de masse par contagion, considérée comme erronée et moralement inacceptable, s'oppose de manière frontale aux recommandations de l'Organisation mondiale de la santé (OMS). L'abandon de l'ancien leadership du Brésil en matière de santé mondiale et de coopération régionale dans le domaine de la santé s'explique également par le caractère idéologique de sa nouvelle politique étrangère et par la militarisation du Ministère de la santé.

Mots clefs: Brésil, Covid-19 ; néo-libéralisme ; santé mondiale ; OMS.

Traducción de Rafael Segovia, CM Idiomas

Fecha de recepción: noviembre de 2020.

Fecha de aceptación: febrero de 2021. 
FI LXI-2 Brasil laboratorio DEL “NEOliberalismo EPIDEMiolóGico” 429

\section{INTRODUCCIÓN}

$\mathrm{L}$

a respuesta brasileña a la pandemia de Covid-19 marca un importante punto de inflexión en la actuación de Brasil en el ámbito de la salud global. Acreditado por su experiencia en políticas exitosas, en particular por su sistema de salud que es una imponente referencia internacional, Brasil ha mantenido desde los años 1990 una posición constructiva, aunque crítica, sobre la gobernanza mundial de la salud. Sin embargo, hoy en día, la política exterior del gobierno de Jair Bolsonaro, detrás de su liderazgo, se caracteriza en este campo por la renuncia al protagonismo en los planes regional y multilateral; por la participación en alianzas nefastas para los derechos humanos, con gobiernos ultraconservadores y dictaduras; por la sumisión a los intereses de Estados Unidos, al menos durante la administración de Donald Trump (2017-2021), y por la importación selectiva y puntual de conductas del expresidente estadounidense con fines propagandísticos. Específicamente en relación a la pandemia de Covid-19, el mimetismo entre Trump y Bolsonaro incluyó, entre otros aspectos, ataques a China y a organizaciones internacionales, en particular a la Organización Mundial de la Salud (oms), y vacilaciones en adherirse al Acelerador del Acceso a las herramientas contra la Covid-19 (Covax), principal instrumento multilateral relativo al acceso a la vacuna contra el virus, lo que Brasil terminó por hacer tardía y limitadamente.

Sin embargo, el importante cambio de la agenda brasileña en el campo de la salud global va más allá de las semejanzas entre dos jefes de Estado populistas de extrema derecha. De manera general, las respuestas de los Estados a la Covid-19 han estado determinadas por acciones y omisiones ocurridas a lo largo de las últimas décadas, las cuales redujeron la capacidad de los sistemas de salud para vigilar, contener y mitigar las epidemias. Esta evolución es el fruto de decisiones políticas que acentuaron la desigualdad económi- 
ca, la precariedad laboral y el debilitamiento de los servicios públicos y colocaron a una parte importante de la población en una situación de vulnerabilidad ante la enfermedad, y de incapacidad para hacer frente a sus consecuencias. ${ }^{1}$ Por esta razón, para analizar el rol de Brasil en la gobernanza mundial y regional de la Covid-19, el presente artículo se suma a los estudios críticos de la salud global, que investigan cómo las configuraciones de poder, instituciones, procesos e ideologías influyen en la forma y en el alcance de los procesos relacionados con la salud y la enfermedad. ${ }^{2}$

En este sentido, se pueden estudiar las emergencias internacionales de salud bajo diferentes perspectivas críticas. João Biehl señala cuatro: un primer cuerpo de estudios críticos entiende la salud global como un proyecto imperial neocolonial o poscolonial, y busca revelar cómo la narrativa triunfante de la globalización perpetúa y oculta viejas dinámicas coloniales; en una segunda línea, la salud global refleja y sostiene un orden mundial capitalista y neoliberal, orientado por el mercado, donde intereses geoeconómicos, sobre todo de actores privados, solapan el interés público; una tercera vertiente está centrada en investigar los nuevos regímenes de gubernamentalidad y bioseguridad que reconfiguran el discurso y la práctica en torno a la salud y al riesgo; y una cuarta que percibe en la salud global la expresión de un humanitarismo transnacional como forma dominante de pensamiento moral en Occidente, que moviliza la compasión ante el sufrimiento de manera potencialmente despolitizadora y que, "en nombre de la humanidad", es capaz de promover o encubrir la desigualdad y la violencia. ${ }^{3}$

${ }^{1}$ João Nunes, “The Covid-19 Pandemic: Securitization, Neoliberal Crisis, and Global Vulnerabilization”, Cadernos de Saúde Pública, vol. 36, núm. 5, 2020, e00063120.

${ }^{2}$ João Biehl y Adriana Petryna, When People Come First: Critical Studies in Global Health, Princeton, University Press, 2013.

${ }^{3}$ João Biehl, "Theorizing Global Health", MAT: Medicine Anthropology Theory, vol. 3, núm. 2, 2016, pp. 127-142. 
Aunque todos estos abordajes son contribuciones importantes, consideramos que Brasil ofrece un ejemplo radical de respuesta a la pandemia según la lógica neoliberal. Por medio de una investigación documental y una revisión de literatura narrativa, y corroborando la tendencia de la bibliografía reciente sobre el papel proactivo de líderes populistas en la diseminación de la pandemia, ${ }^{4}$ demostraremos que hay en Brasil una estrategia institucional de propagación del nuevo coronavirus, liderada por el presidente de la República e implementada por el conjunto del gobierno federal, no sin resistencias de gobiernos locales, instituciones, partidos de oposición y movimientos sociales. Mediante la llamada "inmunidad colectiva", ${ }^{5}$ el gobierno federal pretende reanudar la actividad económica lo antes posible y a cualquier precio. En abril de 2020, comentando las estrategias de respuesta a la pandemia de los Países Bajos y del Reino Unido, Isabel Frey las definió como "neoliberalismo epidemiológico" porque, al igual que la creencia incondicional en el libre mercado, la estrategia de inmunidad colectiva consiste en superar una epidemia con regulación y costos mínimos, aunque se sepa que implicará la muerte de miles de personas, sobre

${ }^{4}$ Ver, por ejemplo, Martin McKee, et al., "Are Populist Leaders Creating the Conditions for the Spread of Covid-19?", International Journal of Health Policy and Management, 2020, pmid:32668893, doi:10.34172/ijhpm. 2020.124 (consulta del 5 de febrero de 2021); David Scheffer, "Is It a Crime to Mishandle a Public Health Response?", Council on Foreign Affairs, 22 de abril de 2020, https://www.cfr.org/article/it-crime-mishand le-public-health -response (consulta del 5 de febrero de 2021); Kamran Abbasi, "Covid-19: Social Murder, They Wrote-Elected, Unaccountable, and Unrepentant", $B M J$, versión en línea, 3 de febrero de 2021, 372:n314 https://doi.org/10. 1136/bmj.n314 (consulta del 4 de febrero de 2021).

${ }^{5}$ Según la oms, la "inmunidad colectiva" o "inmunidad de grupo" es la protección indirecta contra una enfermedad infecciosa que se obtiene cuando una población se vuelve inmune, ya sea como resultado de la vacunación o de haber presentado la infección con anterioridad. Organización Mundial de la Salud (oms), "Inmunidad colectiva, confinamentos y Covid-19", 31 de diciembre de 2020, https://www.who.int/es/news-room/q-a-d etail/herd-immunity-lockdowns-and-covid-19 (consulta del 5 de febrero de 2021). 
todo las más vulnerables. ${ }^{6}$ Sin embargo, a diferencia de los países antes citados, que han modificado sus estrategias iniciales frente al aumento del número de casos y fallecidos, el presidente brasileño y quienes lo apoyan persisten en la idea de que la economía no puede soportar una suspensión, aunque temporal, de la circulación de personas. ${ }^{7} \mathrm{Al}$ hacerlo, establecen artificialmente una oposición entre la protección de la economía y la protección de la salud, que viene siendo un recurso retórico muy común en la defensa de las políticas de austeridad fiscal a lo largo de las últimas décadas cuando, en realidad, el estudio de las políticas sociales de distintos Estados revela que las inversiones públicas en salud presentan un retorno positivo para la economía. ${ }^{8}$

Para demostrar el cambio reciente de la posición de Brasil en su actuación internacional, en la primera parte del artículo presentaremos una muy breve síntesis de sus contribuciones al desarrollo de la arquitectura de la gobernanza mundial y regional, como un defensor de la agenda de los determinantes sociales de la salud. Ésta es una concepción de salud global según la cual la justicia social está en el centro de la salud pública y debe reconocerse y enfrentarse la dimensión mundial de las inequidades en salud. ${ }^{9}$

En la segunda parte, trataremos de explicar el núcleo de la respuesta brasileña a la pandemia, mediante la cual el gobierno se pone a contramano de la mayoría de las respuestas en el plano global, sobre todo en radical oposición a las reco-

${ }^{6}$ Isabel Frey, "'Herd Immunity' is Epidemiological Neoliberalism”, The Quarantines, 19 de marzo de 2020, https:/ / thequarantimes.wordpress. com/2020/03/19/herd-immunity-is-epidemiological-neoliberalism/ (consulta del 5 de febrero de 2021).

${ }^{7}$ João Nunes, op. cit.

${ }^{8}$ David Stuckler y Sanjay Basu, The Body Economic: Why Austerity Kills, Nueva York, Basic Books, 2013.

${ }^{9}$ Anne-Emanuelle Birn, “¿Politizándolo o puliéndolo? Subsanar las desigualdades en una generación: alcanzar la equidad sanitaria actuando sobre los determinantes sociales de la salud”, Medicina Social, vol. 4, núm. 3, 2009, pp. 189-207. 
mendaciones de la oms. Esta estrategia también determina el desinterés de Brasil por la dimensión regional de la gobernanza de la pandemia, lo cual profundiza un proceso de reducción de la importancia del regionalismo que ya se encontraba en curso.

En la tercera parte, buscaremos demonstrar que la estrategia de propagación de la pandemia se combina con la actual orientación ideológica de la política exterior brasileña, que considera la expertise en salud pública como un obstáculo para la elaboración ideologizada de las políticas de salud. Más allá de la actuación de la cancillería, la militarización del Ministerio de la Salud y la paulatina eliminación de los cuadros técnicos en salud pública de la esfera federal del gobierno abren camino para políticas públicas en este ámbito contrarias al principio de laicidad y tienen un potencial impacto negativo sobre los derechos humanos. Además, estas tendencias aniquilan de igual modo un obstáculo interno al liderazgo de Brasil en alianzas internacionales relacionadas con la agenda de valores reaccionarios, en especial en contra de los derechos sexuales y reproductivos de las mujeres.

BRASIL COMO ACTOR TRADICIONAL GONSTRUGTIVO, AUNQUE CRÍTICO DE LA SALUD GLOBAL

Dos perspectivas se enfrentan en la trayectoria de la salud global, que coincide con la expansión del neoliberalismo: una es humanista, considera a los sanitaristas como agentes de cambio social y la salud como un derecho humano, y otra, tecnocrática, implementada por una élite de expertos que consideran la mejora de la salud como una forma de controlar brotes epidémicos, suministrar una atención hospitalaria asistencial y contribuir al desarrollo económico en una sociedad liberal. ${ }^{10}$ En los últimos años, esas dos perspectivas han

${ }^{10}$ João Nunes, op. cit. y Marcos Cueto, "El legado de Alma-Ata, 40 años después”, Trabalho, educação e saúde, vol. 16, núm. 3, 2018, pp. 845-848. 
pasado a conocerse, respectivamente, una como los determinantes sociales de la salud (Dss) ${ }^{11}$ y la otra, de la cobertura universal de salud.

Hasta 2018, Brasil participó activamente en los foros multilaterales y regionales dedicados a las cuestiones de salud como defensor de los Dss. Llegó a acoger, en 2011, en la ciudad de Río de Janeiro, la Conferencia Mundial de la oms sobre Determinantes Sociales de la Salud. ${ }^{12}$ Durante más de dos décadas, la actividad internacional de Brasil hizo hincapié en la promoción de coaliciones entre los países del mundo en desarrollo, incluidas las regionales, en la defensa de una agenda global dirigida a reducir las inmensas desigualdades entre las poblaciones, tanto dentro de cada país como entre los diferentes Estados y regiones; y en la sujeción del comercio internacional a los derechos humanos, sobre todo en materia de propiedad intelectual. ${ }^{13}$

Además del compromiso con el multilateralismo y el regionalismo, la experiencia de tres décadas del Sistema Único de Salud de Brasil (sus) -una compleja estructura federal que proporciona acceso universal y gratuito a la atención a la salud para la mayoría de la población brasileña- ha converti-

${ }^{11}$ Según la oms, los determinantes sociales de la salud son las circunstancias en que las personas nacen, crecen, viven, trabajan y envejecen, incluido el sistema de salud, y que explican la mayor parte de las inequidades sanitarias, esto es, de las diferencias injustas y evitables observadas en y entre los países respecto a la situación sanitaria.

${ }^{12}$ Organización Mundial de la Salud, oms, "Rio Political Declaration on Social Determinants of Health", World Conference on Social Determinants of Health, Río de Janeiro, 2011.

13 Paulo Marchiori Buss, "Brazilian International Cooperation in Health in the Era of SUS", Ciência Eॄ Saúde Coletiva, vol. 23, núm. 6, 2018, pp. 1881-1890; Celia Almeida, "Política externa e cooperação internacional no Brasil: eixos estratégicos e agendas", en Paulo Marchiori Buss y Sebastián Tobar (coords.), Diplomacia da saúde e saúde global: perspectivas latino-americanas, Río de Janeiro, Editora Fiocruz, 2017; Oficina de Asuntos Internacionales de la Salud, Salud y Política Externa: los 20 años de la Oficina de Asuntos Internacionales de Salud (1998-2018). Brasilia, Ministerio de la Salud, 2018, http://bvsms.saude.gov.br/bvs/publicacoes/salud_po litica_externa_20anos_espanhol.pdf (consulta del 5 de febrero de 2021). 
do a Brasil en una referencia internacional en varios ámbitos, incluidos los programas de acceso a medicamentos y la atención primaria de salud. El análisis de los 30 años transcurridos desde la creación del sus muestra una espectacular ampliación de la cobertura de los servicios sanitarios, desafiados por las persistentes desigualdades geográficas, la financiación insuficiente -agravada en 2016 después de que se fijara, en la constitución, un techo máximo de gastos en materia de salud durante el gobierno de Michel Temer (20162018) - y la colaboración problemática entre el sector público y el privado. ${ }^{14}$

Pese a las tensiones y dificultades internas, se puede afirmar que Brasil tuvo, por lo menos entre 2003 y 2014, una verdadera "política exterior de salud", ${ }^{15}$ operada por actores fuera del tradicional ámbito diplomático, a cargo principalmente del Ministerio de Relaciones Exteriores. Varios factores nos permiten afirmarlo: la existencia de actores propios del campo de la salud como, por ejemplo, la Fundación Oswaldo Cruz (Fiocruz), el Instituto Nacional del Cáncer, la Oficina Internacional del Ministerio de la Salud, la Agencia Nacional de Vigilancia en Salud, entre otros, cuya labor era diplomática; la de sus propios principios, vinculados a los del sus, entre éstos la universalidad del derecho a la salud; y la de sus propias agendas, que incluían la búsqueda de una intensa cooperación Sur-Sur (CSs) en el campo de la salud, presuntamente desprovista de las condicionalidades y defectos de la cooperación Norte-Sur.

La cooperación brasileña buscaba desmarcarse de la mayor parte de los programas de salud global, que en general son alianzas entre agentes públicos y privados que manejan

14 Marcia C. Castro, et al., "Brazil's Unified Health System: The First 30 Years and Prospects for the uture”, The Lancet, núm. 10195, 2019, pp. 345-356.

15 Fernanda Aguilar Perez, "A Brazilian Health Foreign Policy? The Role of Health in Brazilian Foreign Affairs", tesis de doctorado, Relaciones Internacionales, São Paulo, Instituto de Relações Internacionais-Universidade de São Paulo/ King's College London, 2018. 
programas impulsados por intereses no siempre claros, en los cuales no es raro que las demandas de los donantes se sobrepongan a las prioridades de los supuestos beneficiarios. ${ }^{16}$ También ha florecido una importante literatura crítica sobre los límites y penurias de la cooperación brasileña, ${ }^{17}$ incluso sobre la eventual explotación predatoria del trabajo humano y de los recursos naturales donde han actuado empresas brasileñas. ${ }^{18}$

Respecto a la oms, Brasil ha tenido una intensa participación a lo largo de su historia, en la que se destacan cuatro aspectos: la acción institucional, el protagonismo en determinadas agendas, la cooperación a nivel nacional y la búsqueda de prestigio político.

En cuanto a la acción institucional, Brasil fue uno de los Estados que propuso la creación de la oms, en 1945, en la Conferencia de San Francisco. ${ }^{19}$ Durante 20 años, entre 1953 y 1973, la oms tuvo un director general brasileño, Marcolino Candau. ${ }^{20}$ Entre otras responsabilidades más recientes, ocupó la presidencia del Consejo Ejecutivo de la oms de 2018 a 2019, y la vicepresidencia de 2010 a 2011. Además, especialistas brasileños y brasileñas independientes son miembros de incontables comisiones de la oms.

En lo que se refiere al protagonismo en determinados temas, Brasil ha presidido las negociaciones de la única convención ${ }^{21}$ hasta la fecha en el ámbito de la oms: el Convenio

${ }^{16}$ João Biehl y Adriana Petryna, op. cit.

${ }^{17}$ Ver, por ejemplo, Paulo Esteves, et al., "A rede de políticas de saúde pública e a cooperação Sul-Sul: os casos de Moçambique e Angola”, Lua Nova, núm. 98, 2016, pp. 199-230.

${ }^{18}$ Deisy Ventura, "Public Health and Brazilian Foreign Policy", suR, vol. 10, núm. 19, 2013, pp. 99-119.

${ }^{19}$ Marcos Cueto, Theodore M. Brown y Elizabeth Fee, The World Health Organization. A History, Cambridge, University Press, 2019.

20 Theodore M. Brown, Marcos Cueto y Elizabeth Fee, "A transição de saúde pública 'internacional' para 'global' e a Organização Mundial da Saúde", História, Ciências, Saúde-Manguinhos, vol. 13, núm. 3, 2006, pp. 623-647.

${ }^{21}$ Convención o acuerdo, en el sentido del artículo 19 de la Constitución de la oms. 
Marco para el Control del Tabaco, aprobado en 2003, cuya negociación estuvo a cargo del excanciller Celso Amorim $(2003-2010){ }^{22}$

Con respecto a la importancia de la oms en los asuntos internos de Brasil, probablemente el mejor ejemplo es el "Proyecto de Cooperación con el Programa Mais Médicos para Brasil". A partir de 2013, la Organización Panamericana de la Salud (ops), que también es la oficina regional de la oms para las Américas, desarrolló esta iniciativa que permitió la contratación de 11400 médicos cubanos, sólo en sus tres primeros años de actividad. ${ }^{23}$ Este programa ha tenido un impacto significativo en la salud pública brasileña, especialmente respecto a la atención primaria, ${ }^{24}$ aunque se haya convertido en objeto de viva oposición, sobre todo de la clase médica brasileña. La sinergia entre Brasil y la ops también fue evidente durante la emergencia internacional relacionada con el Síndrome Congénito de Zika, cuyo epicentro fue el propio Brasil, en 2016. ${ }^{25}$

Por último, sobre la búsqueda de prestigio político, recordamos que en marzo de 2018 el director de la oms, Tedros Adhanom, recibió del expresidente Michel Temer la "Medalla al Mérito Oswaldo Cruz", concedida en una ceremonia

${ }^{22}$ Luiz Antônio Teixeira da Silva, Carlos Henrique Assunção Paiva y Vanessa Nolasco Ferreira, "The World Health Organization Framework Convention on Tobacco Control in the Brazilian Political Agenda, 20032005”, Cadernos de Saúde Pública, vol. 33, supl. 3, 2017, e00121016.

${ }^{23}$ Joaquín Molina, Renato Tasca y Julio Suárez, "Monitoring and Evaluation of the PAHO/WHO Cooperation Project, the Mais Médicos (More Doctors) Program: A Mid-Term Assessment", Ciência Ẽ Saúde Coletiva, vol. 21, núm. 9, 2016, pp. 2925-2933.

${ }^{24}$ Allan Barbosa, et al., "Programa Mais Médicos: como avaliar o impacto de uma abordagem inovadora para superação de iniquidades em recursos humanos", Revista Panamericana de Salud Pública, vol. 42, núm. 185, 2018, pp. 1-8.

${ }^{25}$ Secretaría de Vigilancia en Salud, svs, Zika Virus in Brazil: The SUS Response, Ministerio de la Salud, 2017, http://www.saude.gov.br/images/ pdf/2017/setembro/21/zika-virus-in-brazil-2017.pdf (consulta del 3 de febrero de 2021). 
oficial en el Palacio del Planalto, en reconocimiento de la labor realizada por la oms en Brasil. ${ }^{26}$ Pese a que se trataba de un gobierno conservador, que ya avanzaba tanto en las políticas de austeridad fiscal como en la agenda de valores reaccionarios en el campo de la salud, buscaba en su política exterior mantener buenas relaciones con los organismos internacionales, incluyendo la oms. Aunque incompleta, esta síntesis de la actuación de Brasil en relación con este organismo internacional ya es suficiente para indicar el impacto del cambio que se está produciendo con el gobierno de Jair Bolsonaro desde 2019.

En el plano regional, el Brasil fue uno de los líderes en la creación de la Unión de Naciones Suramericanas (Unasur) en 2008, que comprendía los 12 países de América del Sur. ${ }^{27}$ En particular, desde el segundo mandato de la presidenta Dilma Rousseff (2014-2016), ya debilitada por la crisis política y económica que se agudizaba, dio inicio a un cambio explícito de dirección en la política exterior brasileña, especialmente en lo que se refiere a la idea de América del Sur, con preferencia por acuerdos regionales más flexibles. ${ }^{28}$ Este cambio se puso de manifiesto con la creación del Foro para el Progreso y la Integración de América del Sur (Prosur), en marzo de 2019, por los presidentes de Argentina, Brasil, Chile, Colombia, Ecuador, Guyana, Paraguay y Perú, ${ }^{29}$

26 Victor Maciel, “oms e diretores recebem homenagem do Governo Federal”, Ministerio de la Salud, 21 de marzo de 2018, https:/ /www.saude. gov.br/noticias/agencia-saude/42856-oms-e-diretores-recebem-homena gem-do-governo-federal (consulta del 3 febrero de 2021).

27 Javier A. Vadell y Clarissa Giaccaglia, "El rol de Brasil en el regionalismo latinoamericano: la apuesta por una inserción internacional solitaria y unilateral", Foro Internacional, vol. 60, núm. 3, 2020, pp. 1041-1080.

28 Javier A. Vadell y Clarissa Giaccaglia, op. cit.

29 Ministerio de Relaciones Exteriores, "Declaração Presidencial sobre a Renovação e o Fortalecimento da Integração da América do Sul”, 22 de marzo de 2019, http:/ / www.itamaraty.gov.br/pt-BR/notas-a-impren sa/20203-declaracao-presidencial-sobre-a-renovacao-e-o-fortalecimentoda-integracao-da-america-do-sul (consulta del 3 de febrero de 2021). 
al mismo tiempo que sus gobiernos solicitaron su salida de Unasur.

En la práctica, en 2019 culminaron las actividades de una de las experiencias más exitosas de integración regional en el campo de la salud, el Instituto Suramericano de gobierno en Salud (Isags), con sede en Río de Janeiro, lo anterior como resultado de la extinción de Unasur. Además de ser un centro de altos estudios, el Isags promovió durante años la producción de conocimiento y la creación de redes de personal técnico, en apoyo al Consejo de Salud Sudamericano que reunió a las más altas autoridades sanitarias de cada país, promoviendo "una revolución silenciosa en la diplomacia de la salud en Sudamérica". ${ }^{30}$

En las últimas dos décadas, por diversos motivos, entre ellos la ambición de acoger varios acontecimientos internacionales importantes, como la Copa del Mundo de la Federación Internacional de Futbol (FIFA) en 2014 y los Juegos Olímpicos y Paralímpicos en 2016, Brasil ha estado invirtiendo en el desarrollo de su capacidad de respuesta a emergencias sanitarias. ${ }^{31}$ En el marco de esa preparación, el Estado buscó, especialmente mediante el perfeccionamiento del sus, adquirir o mejorar las capacidades nacionales de respuesta previstas en el Reglamento Sanitario Internacional (RSI), que fue adoptado por la Asamblea Mundial de la Salud, órgano superior de la oms, en mayo de 2005 y entró en vigor en junio de 2007. ${ }^{32}$ Se ha reconocido extensamente el cumplimiento de las normas internacionales del sistema brasileño de vigilancia sanitaria. Por ejemplo, a finales de 2019, el Índice de Seguridad Sanitaria Mundial, de la prestigiosa Es-

${ }^{30}$ María Belén Herrero y Diana Tussie, "Unasur Health: A Quiet Revolution in Health Diplomacy in South America”, Global Social Policy, vol. 15, núm. 3, 2015, pp. 261-277.

${ }^{31}$ Secretaría de Vigilancia en Salud, svs, Vigilância em saúde: ações inovadoras e resultados: gestão 2011-2014, Brasilia, Ministerio de la Salud, 2015.

32 Eduardo Hage Carmo, Gerson Penna y Wanderson Kleber de Oliveira, "Emergências de saúde pública: conceito, caracterização, preparação e resposta”, Estudos avançados, vol. 22, núm. 64, 2008, pp. 19-32. 
cuela de Salud Pública Bloomberg de la Universidad Johns Hopkins, clasificó Brasil en el puesto 22 de 195 países en la clasificación general de seguridad sanitaria; en el 12. ${ }^{\circ}$ lugar en materia de detección y notificación tempranas de eventos con potencial de propagación internacional; y en el $9 .^{\circ}$ en respuesta rápida y mitigación de la propagación de una epidemia. ${ }^{33}$ De hecho, el comienzo de la respuesta brasileña a la Covid-19 había cumplido las expectativas: el 3 de febrero, aún sin casos confirmados en su territorio, Brasil declaró una emergencia nacional de salud pública y adoptó un conjunto de disposiciones para contener el virus. ${ }^{34}$ No obstante, a lo largo de las semanas siguientes prevaleció la posición opuesta en el gobierno federal, que describiremos a continuación.

\section{"NEOLIBERALISMO EPIDEMIOLÓGICO": CONFRONTACIÓN ABIERTA CON LA OMS E INDIFERENCIA HACIA LA REGIÓN EN 2020}

Un estudio reciente, coordinado por una de las autoras de este artículo, disipa la ingenua y persistente interpretación según la cual el gobierno brasileño es incompetente o negligente al gestionar la pandemia. Muy al contrario, el estudio demuestra en orden cronológico la actuación sistemática de los órganos federales, desde marzo de 2020 hasta el 16 de enero de

${ }^{33}$ Nuclear Threat Initiative/The Johns Hopkins Center for Health Security, Gloval Health Security Index. Building Collective Action and Accountability, 2019, https://www.ghsindex.org/wp-content/uploads/2019/10/2019 -Global-Health-Security-Index.pdf (consulta del 5 de febrero de 2021).

34 Sobre el inicio de la respuesta brasileña, véase Cláudio Maierovitch Pessanha Henriques y Wagner Vasconcelos, "Crises dentro da crise: respostas, incertezas e desencontros no combate à pandemia da Covid-19 no Brasil”, Estudos avançados, vol. 34, núm. 99, 2020, pp. 25-44 y Julio Henrique Rosa Croda y Leila Posenato Garcia, "Immediate Health Surveillance Response to Covid-19 Epidemic", Epidemiologia e Serviços de Saúde, vol. 29, núm. 1, 2020, e2020002. 
2021, e identifica la presencia de tres ejes que se siguieron y se explican brevemente a continuación. ${ }^{35}$

El primer eje comprende una intensa actividad normativa, que incluye la emisión de normas por autoridades y órganos federales (por ejemplo, la norma que atribuía al presidente de la República la competencia para definir los servicios públicos y actividades esenciales durante la pandemia, cuya eficacia fue revertida por la Suprema Corte y más adelante por el Congreso Nacional) y los vetos presidenciales (por ejemplo, a las leyes que instituían la obligatoriedad del uso de mascarillas, el plan nacional de protección de las comunidades indígenas, la extensión del auxilio financiero de emergencia a categorías de trabajadores para que pudieran permanecer en sus domicilios y la compensación financiera a las familias de profesionales de salud fallecidos en el combate a la enfermedad).

El segundo eje comprende los actos de obstrucción a las respuestas a la pandemia de los estados federados y de los municipios, que incluye la declaración pública de "guerra a los gobernadores" 36 que adoptaran medidas cuarentenarias, tentativas de confiscación de insumos médicos adquiridos por estados y municipios, y retrasos injustificados en la transferencia de recursos a los gobiernos locales.

El tercer eje es la propaganda en contra de la salud pública, definida como el discurso político que moviliza argumentos económicos, ideológicos y morales, además de no-

35 Deisy Ventura y Rossana Reis, "An Unprecedented Attack on Human Rights in Brazil: The Timeline of the Federal Government's Strategy to Spread Covid-19”, Bulletin Rights in the Pandemic, núm. 10, Offprint, São Paulo, Cepedisa-usp/Conectas Direitos Humanos, enero de 2021, https:/ / www.conectas.org/wp/wp-content/uploads/2021/01/10boletimcovid_ english_03.pdf (consulta del 6 de febrero de 2021).

36 Ricardo Della Coletta, Bernardo Karam y Gustavo Uribe, "É guerra, tem que jogar pesado com governadores, diz Bolsonaro a empresários", Folha de São Paulo, 14 de mayo de 2020, https:/ /www1.folha.uol.com.br/ poder / 2020/05/e-guerra-tem-que-jogar-pesado-com-governadoresdiz-bolsonaro-a-empresarios.shtml (consulta del 5 de febrero de 2021). 
ticias falsas e información técnica sin respaldo científico, con el propósito de desacreditar a las autoridades sanitarias, debilitar la adhesión popular a las recomendaciones sanitarias basadas en pruebas científicas y promover el activismo político contra las medidas de salud pública necesarias para contener el avance de la Covid-19. Se efectúa, entre otras maneras, por la conducta del presidente, que suele no portar mascarillas y promueve continuamente la reunión de aglomeraciones en su entorno, donde busca el contacto físico con quienes lo apoyan; el negacionismo científico, la difusión de noticias falsas y la incitación constante a la población a exponerse al virus, presente en la comunicación oficial del presidente y de otros órganos de gobierno, incluso del Ministerio de la Salud; la descalificación de científicos, expertos y de las autoridades sanitarias; y la controversia acerca del uso precoz de medicamentos de comprobada ineficacia para tratamiento de la Covid-19, sobretodo la hidroxicloroquina.

Desde el inicio de la pandemia, el presidente y sus aliados más cercanos defendieron explícitamente el "aislamiento vertical”, un concepto inexistente en la bibliografía científica, que consistiría en suspender las medidas generales de control epidemiológico, aislando sólo a los grupos vulnerables, los ancianos y a las personas con comorbilidades, lo que de inmediato cuestionaron expertos de varias disciplinas. ${ }^{37}$

Esta estrategia confronta radicalmente la posición de la oms, según la cual "nunca en la historia de la salud pública se ha recurrido a la inmunidad colectiva como una estrategia para responder a un brote, y mucho menos a una pandemia. Ello plantearía problemas científicos y éticos. [...]. [D] ejar que el virus circule descontroladamente supone infecciones, sufrimientos y muertes innecesarios [...]. Permitir que un virus peligroso, cuyos mecanismos no conocemos ca-

${ }^{37}$ Naomar Almeida-Filho, "Pandemia de Covid-19 no Brasil: equívocos estratégicos induzidos por retórica negacionista”, en Principais elementos, Brasilia, Conselho Nacional de Secretários de Saúde, 2021, pp. 214-225, http://www.rets.epsjv.fiocruz.br/sites/default/files/arquivos/bibliote ca/covid-19-volume1.pdf (consulta del 6 de febrero de 2021). 
balmente, circule sin control es algo contrario a la ética. Ésa no es una opción [...]. No es una elección entre dejar que el virus circule libremente o paralizar nuestras sociedades". ${ }^{38}$

Hay paralelos entre la respuesta brasileña y las posiciones de Donald Trump, considerado un "determinante político de la Covid-19" por haber desacreditado a las autoridades sanitarias de su propio gobierno, difundiendo mentiras y atacando a los gobiernos locales que reconocían la gravedad de la enfermedad, llegando a fomentar la insurrección popular para "liberar" estos estados, incluso el alzamiento en armas. ${ }^{39}$ Una secuencia de críticas y amenazas a la oms pronunciadas por Trump culminó con la notificación oficial del retiro de Estados Unidos de la organización en julio de 2020.

El presidente de Brasil reprodujo las amenazas de retirarse de la oms expresadas por Trump en mayo del mismo año, con el pretexto de que la organización tendría un "sesgo ideológico". ${ }^{40}$ Otros miembros del gobierno federal han hablado constantemente contra la oms, sobre todo el canciller, Ernesto Araújo, para quien "transferir poderes nacionales a la oms, con el pretexto (¡nunca probado!) de que un organismo internacional centralizado es más eficiente para tratar los problemas que los países que actúan individualmente, es sólo el primer paso para construir la solidaridad comunista planetaria", antes de añadir, "lo políticamente correcto incorpora lo sanitariamente correcto, muchas veces más poderoso", debido a que "el comunismo de repente en-

38 oms, "Alocución de apertura del Director General de la oms en la conferencia de prensa sobre la COVID-19 del 12 de octubre de 2020", 12 de octubre de 2020, https://www.who.int/es/director-general/speeches/ detail/who-director-general-s-opening-remarks-at-the-media-briefingon-covid-19-12-october-2020 (consulta del 4 de febrero de 2021).

${ }^{39}$ Gavin Yamey y Gregg Gonsalves, "Donald Trump: A Political Determinant of Covid-19”, BMJ, núm. 369, 2020, m1643, https:/ /www.bmj.com/ content/369/bmj.m1643 (consulta del 3 de febrero de 2021).

40 Pedro Vilela, "Bolsonaro diz que Brasil pode sair da OMS", Agência Brasil, 5 de junio de 2020, https://agenciabrasil.ebc.com.br/politica/ noticia/2020-06/bolsonaro-diz-que-brasil-pode-sair-da-oms (consulta del 3 de febrero de 2021). 
contró en el coronavirus un tesoro de opresión”. ${ }^{41}$ Más allá del discurso, Brasil acumula una creciente deuda con la organización. ${ }^{42}$

Pese a su retórica en contra de la oms, Brasil fue uno de los beneficiarios de las acciones de la ops, que reaccionó rápidamente como referencia de intercambio técnico regional sobre la respuesta a la pandemia. Además de la información epidemiológica, las actividades de capacitación, la formulación de directrices técnicas y el material de comunicación, la ops intermedió, por medio de su Fondo Estratégico, la compra de 10 millones de pruebas, y participó directamente en la organización de la respuesta de varios gobiernos locales. ${ }^{43}$

Por otra parte, las medidas de salud pública adoptadas por los gobiernos locales, especialmente la suspensión de las actividades no esenciales, se basaron fundamentalmente en las recomendaciones de la oms, que también fueron la guía de las decisiones judiciales que garantizaron la adopción de esas medidas en varios lugares, o incluso las impusieron. Debe subrayarse la resistencia de los gobiernos locales. El Consórcio do Nordeste, alianza entre los nueve estados de la región creada en marzo de 2019 como herramienta para atraer inversiones, hacer compras conjuntas e integrar políticas públicas, creó un comité científico conjunto para combatir el coronavirus, con destacada actuación. ${ }^{44}$ El gobierno

41 Ernesto Araújo, "Chegou o comunavírus", Metapolítica 17, 22 de abril de 2020, https://www.metapoliticabrasil.com/post/chegou-o-comu nav\%C3\%ADrus (consulta del 3 de febrero de 2021).

42 Jamil Chade, "Brasil deve R $\$ 169$ milhões para oms; Dívida é quarta maior da agência", UOL, 8 de abril de 2020, https://noticias.uol.com. br/colunas/jamil-chade/2020/04/08/brasil-deve-r-169-milhoes-para -oms-divida-e-quarta-maior-da-agencia.htm\#: :text=Brasil $\% 20$ deve $\% 20$ R\% 24\% 20169\% 20milh\% C3\% B 5es, \% 2F04\% 2F 2020\% 20\% 2D \% 20 UOL \%20Not\%C3\%ADcias (consulta del 3 de febrero de 2021).

43 Organización Panamericana de la Salud (ops), "Folha informativa COVID-19", 2020, https://www.paho.org/pt/Covid19 (consulta del 15 de enero de 2021).

${ }^{44}$ Comité Científico de Combate a la Covid-19 del Consocio Nordeste, "Comitê científico de combate ao Coronavírus", 2020, https://www. comitecientifico-ne.com.br/ (consulta del 3 de febrero de 2021). 
de Maranhão, por ejemplo, estableció una negociación directa con China para adquirir respiradores. ${ }^{45}$

Pero las resistencias no han podido evitar el éxito de la estrategia federal de diseminación del virus. Brasil es considerado hoy día como uno de los países con las peores respuestas a la pandemia a nivel mundial, ${ }^{46}$ con más de 10 millones de casos confirmados y casi 245000 muertes al 20 de febrero del 2021. ${ }^{47}$ Según datos de la oms, el 4 de febrero de 2021, más de una de cada diez personas muertas por la Covid-19 en el mundo son brasileñas. ${ }^{48}$ En la comunidad internacional, a menudo se considera al presidente de la República como una amenaza para la salud pública, ${ }^{49}$ y se reconoce el colapso del antiguo liderazgo brasileño. ${ }^{50}$

En el plan regional, la pandemia ha encontrado una América Latina debilitada por un crecimiento económico modesto; con un sector público, incluida la salud, más frágil como consecuencia de las políticas de austeridad fiscal; con mayor inestabilidad política que en la década anterior, y debilitada en sus vínculos regionales por el desmoronamiento de estructuras como la Unasur, el Mercado Común del Sur (Mercosur), la Organización de Estados Americanos (OEA) y la tímida

45 Alexandre Andrade Alvarenga, et al., "Desafios do estado brasileiro frente à pandemia pela Covid-19: o caso da paradiplomacia maranhense", Cadernos de Saúde Pública, vol. 36, núm. 12, 2020, e00155720.

${ }^{46}$ Véase, por ejemplo, Lowy Institute, "Covid Performance Index", https://interactives.lowyinstitute.org/features/covid-performance/\#ran kings (consulta del 5 de febrero de 2021).

${ }^{47}$ Ministerio de la Salud, "Painel Coronavírus", 2020, https://covid. saude.gov.br/ (consulta del 20 de febrero de 2021).

${ }^{48}$ Organización Mundial de la Salud, oMs, "WHO Coronavirus Disease (Covid-19) Dashboard", 2021, https://covid19.who.int/ (consulta del 4 de febrero de 2021).

49 "Covid-19 in Brazil: 'So What?’”, Editorial, The Lancet, núm. 10235, 9 de mayo de 2020, p. 1461.

${ }^{50}$ Francisco Ortega y Michael Orsini, "Governing Covid-19 without Government in Brazil: Ignorance, Neoliberal Authoritarianism, and the Collapse of Public Health Leadership", Global Public Health, vol. 15, núm. 9, 2020 pp. 1257-1277. 
puesta en marcha de la Comunidad de Estados Latinoamericanos y Caribeños (Celac). ${ }^{51}$ En América del Sur prevalece una ausencia total de coordinación, en la que se sustituyó la anterior potencia de Unasur por una formación híbrida y declaratoria como lo es el ya citado Prosur, que deja a la región sin parámetros comunes para hacer frente a la pandemia. ${ }^{52}$

La falta de liderazgo brasileño es evidente. En el inicio de la pandemia, ni siquiera la posibilidad de repatriación de brasileños que se encontraban en China fue extendida a los nacionales de los países de la región, como cabría esperar. ${ }^{53}$ Según el canciller, hubo coordinación regional de la respuesta a través de Prosur y de relaciones bilaterales. ${ }^{54}$ Sin embargo, en el apogeo de la crisis, el presidente no asistió a la reunión de Prosur. En una declaración, Prosur reconoció la importancia de la ops para la región y sostuvo la importancia de la cooperación, ${ }^{55}$ pero a esta declaración no le siguió una aplicación digna de mención. Brasil se mostró tímido a

${ }^{51}$ Nísia Trinidade Lima, Paulo Marchiori Buss y Rômulo Paes-Souza, "A pandemia de Covid-19: uma crise sanitária e humanitária", Cadernos de Saúde Pública, vol. 36, núm. 7, 2020, pp. 1-4.

${ }^{52}$ Pía Riggirozzi, "Coronavirus y el desafío para la gobernanza regional en América Latina”, Análisis núm. 12, Fundación Carolina, 2020.

${ }^{53}$ Ministerio de Relaciones Exteriores/Ministerio de Defensa, "Nota Conjunta do Ministério de Relações Exteriores e Ministério da Defesa", 8 de febrero de 2020, http://www.itamaraty.gov.br/pt-BR/notas-a-impren sa/21299-nota-conjunta-do-ministerio-das-relacoes-exteriores-e-do-minis terio-da-defesa (consulta del 3 de febrero de 2021).

${ }^{54}$ Ministerio de Relaciones Exteriores, "Participação do ministro Ernesto Araújo na $34^{a}$ Reunião do Conselho de Governo", 9 de junio de 2020, http:/ /www.itamaraty.gov.br/pt-BR/discursos-artigos-e-entrevistas-ca tegoria/ministro-das-relacoes-exteriores-discursos/21561-participa cao-doministro-ernesto-araujo-na-34-reuniao-do-conselho-de-governo-9-de-jun ho-de-2020 (consulta del 3 de febrero de 2021).

${ }^{55}$ Ministerio de Relaciones Exteriores, "Declaração presidencial do PROSUL sobre ações conjuntas para enfrentar a pandemia do coronavírus", 16 de marzo de 2020, http://www.itamaraty.gov.br/pt-BR/notas-a -imprensa/21460-declaracao-presidencial-do-prosul-sobre-acoes-conjuntas-para-enfrentar-a-pandemia-do-coronavirus-2 (consulta del 3 de febrero de 2020). 
la hora de aprovechar las redes existentes, ofreciendo únicamente algunas iniciativas de capacitación a sus vecinos, con el apoyo de la ops y de Fiocruz. ${ }^{56}$

Finalmente, en el plan regional, Brasil fue objeto de una medida cautelar de la Comisión Interamericana de Derechos Humanos (CIDH) de protección a los miembros de los pueblos indígenas yanomami e ye'kwana, que se encuentran en una situación grave y urgente ante la pandemia de Covid-19, teniendo en cuenta, entre otros aspectos, el rápido crecimiento del contagio en su territorio; la presencia ilegal de unos 20000 mineros en su zona, fomentando el flujo del virus desde las comunidades urbanas, y los actos de violencia de los mineros contra la población indígena, especialmente hacia sus dirigentes. ${ }^{57}$

En septiembre de 2020, todos los países fronterizos todavía tenían prohibida la entrada de brasileños a su territorio. El país que una vez promovió y acogió al Isags y su visión crítica de la gobernanza global de la salud, se ha rebajado a punto de recibir la donación oficial de dos millones de dosis de hidroxicloroquina, las cuales fueron rechazadas por su entonces aliado estadounidense. ${ }^{58}$

La ausencia dramática de cooperación regional se revela sobre todo en el tema de las vacunas. El Programa Nacional de Inmunización (PNI) brasileño es el más grande del mundo y tiene una capilaridad y expertise innega-

${ }^{56}$ Vinicius Freire, "Fiocruz e OPAS promovem capacitação para diagnóstico do novo coronavírus", Portal Fiocruz, 3 de febrero de 2020, https:// portal.fiocruz.br/noticia/fiocruz-e-opas-promovem-capacitacao-paradiagnostico-do-novo-coronavirus (consulta del 5 de febrero de 2021).

${ }^{57}$ Comisión Interamericana de Derechos Humanos (CIDH), "Membros dos Povos Indígenas Yanomami e Ye'kwana em relação ao Brasil", Resolución 35/2020, 17 de julio de 2020.

58 Andeia Verdélio, "Brasil recebe 2 milhões de doses de hidroxicloroquina dos EUA - Países farão testes do medicamento no tratamento da covid-19”, Agência Brasil, 1 de junio de 2020, https://agenciabrasil.ebc.com. $\mathrm{br} /$ politica/noticia/2020-06/brasil-recebe-dois-milhoes-de-doses-de-hi droxicloroquina-dos-eua (consulta del 3 de febrero de 2021). 
bles. ${ }^{59}$ Sin embargo, coherente en su propósito de promover la inmunidad colectiva por contagio, el presidente pospuso lo más posible la compra de vacunas. Por presión del poder judicial y de la oposición, solamente en diciembre de 2020 se presentó un plan nacional de vacunación, y con lagunas preocupantes. ${ }^{60}$ Brasil tampoco participó activamente en la ya citada covax, incorporándose solamente a fines de septiembre de ese año. Las dificultades en la adquisición de dosis e insumos para la fabricación de vacunas junto a países como China, India y Rusia revela los límites de la diplomacia ideológica en curso, incapaz de movilizar suficientemente a sus aliados en el ámbito del BRICs. ${ }^{61}$ Se esperaba que los logros de los BRICs en el campo del desarrollo de vacunas remodelase el mercado mundial de las vacunas y acelerase el acceso a éstas en el mundo en desarrollo, ${ }^{62}$ pero tales expectativas todavía no se han traducido en medidas estratégicas y resultados concretos. Un obstáculo importante a la actuación brasileña en el campo de la cooperación internacional en salud es la substitución en la esfera federal de gobierno, de funcionarios con formación adecuada, con protagonismo previo en reuniones técnicas internacionales y experiencia en la respuesta a epidemias, por militares subordinados al presidente de la República.

${ }^{59}$ Maria da Conceição Nascimento Costa, et al., "Mortalidade infantil no Brasil em períodos recentes de crise econômica”, Revista de Saúde Pública, vol. 37, núm. 6, 2003, pp. 699-706.

${ }^{60}$ Ministerio de la Salud, "Plano Nacional de Operacionalização da Vacinação contra a Covid-19”, 1ra versión, 16 de diciembre de 2020, https://www.gov.br/saude/pt-br/media/pdf/2020/dezembro/16/pla no_vacinacao_versao_eletronica-1.pdf (consulta del 20 de diciembre de 2020.

${ }^{61}$ Grupo que reúne Brasil, Rusia, India, China y Sudáfrica.

62 Miloud Kaddar, Julie Milstien y Sarah Schmitt, "Impact of BRICS' Investment in Vaccine Development on the Global Vaccine Market", Boletín de la oмs, vol. 92, núm. 6, 2014, pp. 385-446. 
FI LXI-2 Brasil laboratorio del “NEOliberalismo EPIDEMiolóGico” 449

\section{LA MILITARIZACIÓN COMO DETERMINANTE IDEOLÓGICO DE LAS POLÍTICAS DE SALUD}

Un elemento importante del cambio de posición de Brasil sobre la salud global, con especial impacto en la respuesta a la pandemia, es la militarización del Ministerio de la Salud. Mientras estuvo a cargo del cuerpo técnico y de expertos al servicio de la institución, la respuesta brasileña a la pandemia tuvo dos ejes centrales: el sus y el marco reglamentario de la oms. El ministro de Salud, en el momento de la declaración de la emergencia, el médico Luiz Henrique Mandetta, no hacía parte de la llamada vertiente ideológica del gobierno. Al contrario, se trata de un político experimentado, vinculado al partido conservador Democratas (DEM) y a los intereses del sector privado, lo que incluye una actuación parlamentaria a favor de las políticas de austeridad y la subfinanciación crónica del sus. ${ }^{63}$ A la cabeza de un ministerio muy codiciado, por su presupuesto multimillonario y una intensa conexión con los gobiernos locales debido a su estructura descentralizada, Mandetta declaró en 2019 que cuestionaría la universalidad del sistema, garantizada por la Constitución federal. ${ }^{64}$ Sin embargo, ante la emergencia en curso, con la inminencia de una pandemia, era patente que la existencia del sus ponía a Brasil, según el ministro, "por delante de las naciones desarrolladas en la lucha contra el virus". ${ }^{65}$ Así, a partir de febrero

${ }^{63}$ Afonso Benites y Naira Galarraga Gortázar, "Mandetta, o conservador que vestiu o colete do sus e entrincheirou Bolsonaro", El País, 5 de abril de 2020, https://brasil.elpais.com/brasil/2020-04-04/mandetta-oconservador-que-vestiu-o-colete-do-sus-e-entrincheirou-bolsonaro.html (consulta del 3 de febrero de 2021).

${ }^{64}$ Priscila Carvalho, "sus pago? Entenda falas 'polêmicas' do ministro da Saúde em programa da Tv Cultura", voL, 28 de mayo de 2019, https:/ / www.uol.com.br/vivabem/noticias/redacao/2019/05/28/sus-pago-entenda-falas-do-ministro-da-saude-em-programa-da-tv-cultura.htm (consulta del 3 de febrero de 2021).

65 Paula Cristina, "Ainda bem que temos o SUS", Isto é Dinheiro, 28 de febrero de 2020, https://www.istoedinheiro.com.br/ainda-bem-que-temos -o-sus/ (consulta del 3 de febrero de 2021). 
de 2020, Mandetta comenzó a usar el chaleco con el símbolo del sus que lo asociaba a los trabajadores del sistema, ${ }^{66}$ y multiplicó en sus intervenciones públicas frases como "afortunadamente tenemos el sus". ${ }^{67}$ Con una postura técnica y una estrategia de comunicación ofensiva, tuvo una sucesión de enfrentamientos públicos con un presidente cada vez más negacionista. Mandetta sostuvo, por ejemplo, en un artículo científico firmado con parte de su equipo técnico, que Brasil estaba siguiendo las recomendaciones de la oms, a pesar de las peculiaridades locales. ${ }^{68}$ Un distinguido sanitarista brasileño, Naomar Almeida-Filho, considera que Mandetta "fue despedido [el 16 de abril de 2020] y expuesto a la humillación pública por seguir las orientaciones de la oms". 69

Más que una rivalidad personal, la renuncia de Mandetta fue necesaria para que se pusiera en marcha la decisión del presidente de promover la rápida propagación de la enfermedad como forma de reducir al mínimo los daños electorales y económicos de la emergencia. En un año de elecciones municipales, los gobiernos locales se verían obligados a evitar el colapso del sistema de salud en sus ciudades, y seguirían soportando la carga de adoptar medidas para suspender las actividades no esenciales y restringir los derechos, lo que de hecho ocurrió en casi todo el territorio nacional.

El uso temprano de la cloroquina y de la hidroxicloroquina es un elemento fundamental de esta estrategia. Mandetta resume la posición del presidente: "Con esta cajita en la mano

${ }^{66}$ Jussara Soares, "Mandetta vê crescer seu capital político e até 'colete' colabora com popularidade", Terra, 4 de abril de 2020, https:/ / www. terra.com.br/noticias / coronavirus / mandetta-ve-crescer-seu-capital-politi co-e-ate-colete-colabora-com-popularidade,9391bb411915768395644290 bbc58c03i5g6bs1t.html (consulta del 3 de febrero de 2021).

67 Paula Cristina, op. cit.

68 Julio Croda, et al, "Covid-19 in Brazil: Advantages of a Socialized Unified Health System and Preparation to Contain Cases", Revista da Sociedade Brasileira de Medicina Tropical, vol. 53, 17 de abril de 2020, e20 200167.

${ }^{69}$ Naomar Almeida-Filho, op. cit. 
los trabajadores volverán a trabajar, volverán a producir"; 70 pretende "que la gente crea en el medicamento, para ver si vuelven a trabajar, creyendo que el medicamento puede hacer un milagro". ${ }^{71} \mathrm{El}$ exministro también describe el intenso cabildeo de los llamados "médicos bolsonaristas", es decir, médicos que estaban dispuestos a decir lo que el presidente quería escuchar, a cambio de notoriedad, cargos y beneficios del gobierno, invariablemente vinculados al sector privado.

Con la dimisión de Mandetta, Bolsonaro nombró como nuevo ministro de Salud al desconocido médico Nelson Teich, también vinculado al sector privado de la salud, que permaneció en el cargo durante un mes. Su breve gestión se caracterizó por la creciente militarización del ministerio y por el traslado definitivo a la Presidencia del centro de decisión sobre la pandemia. Sin embargo, pese a su perfil bajo, Teich se negó a firmar el protocolo que recomendaba el uso temprano de la cloroquina y la hidroxicloroquina para los casos leves y moderados de la Covid-19.

Así, la militarización de la cartera se ha establecido como la alternativa más viable, asegurando no sólo a través de la alineación política, sino también mediante la manifiesta incapacidad técnica, el control absoluto de la respuesta del presidente. Hasta el final del primer semestre de 2020, ya eran 25 los puestos de dirección o técnicos de alto nivel del Ministério de la Salud ocupados por militares, 21 de los cuales carecían de cualquier experiencia previa en salud. ${ }^{72}$ Sin embargo, es importante registrar que la participación de las Fuerzas Armadas en la respuesta de emergencia había iniciado ya en febrero de 2020, con la "Operación Regreso al

${ }^{70}$ Luiz Henrique Mandetta, Um paciente chamado Brasil, Río de Janeiro, Objetiva, 2020, p. 145.

71 Dagmara Spautz, "Mandetta: 'Cloroquina nunca teve viés de saúde"”, NCS Total, 23 de julio de 2020, https://www.nsctotal.com.br/colunis tas/dagmara-spautz/mandetta-cloroquina-nunca-teve-vies-de-saude (consulta del 3 de febrero de 2021).

72 Diego de Oliveira Souza, “A militarização do Ministério da Saúde no Brasil”, Revista Uruguaya de Ciencia Política, vol. 29, núm. 2, 2020, pp. 33-54. 
Amado País Brasil", una acción interministerial ocurrida, dirigida por la Fuerza Aérea Brasileña con el objetivo de repatriar a 34 brasileños que se encontraban en Wuhan, China, el epicentro inicial del nuevo coronavirus. ${ }^{73}$ Meticulosamente planeada por las Fuerzas Armadas, ${ }^{74}$ la repatriación fue una gran operación de propaganda gubernamental donde la búsqueda de protagonismo de los militares se vio contrastada con su ineptitud técnica expresada en numerosos errores, entre ellos la dispensa de confinamiento de la tripulación de la aeronave y la creación de un área de convivencia entre los rescatados, confinados en una base militar de la ciudad de Anápolis, en Goiás. ${ }^{75}$

Después de meses como ministro interino, el general Eduardo Pazuello, hombre de confianza de Bolsonaro, sin formación ni experiencia para su cargo, fue nombrado definitivamente Ministro de la Salud en septiembre de 2020. En su discurso inaugural, desacreditando a las autoridades sanitarias locales, criticó las medidas de distanciamiento físico y abogó por el uso temprano de la cloroquina. ${ }^{76}$ Reconoció recientemente que antes de ser ministro "ni siquiera sabía lo que era el sus". ${ }^{77} \mathrm{El}$ resultado es que nunca el Estado brasi-

${ }^{73}$ Fuerza Aérea Brasileña, "Operação Regresso à Pátria Amada Brasil”, 2020, https://www.fab.mil.br/operacaoregresso/ (consulta del 3 de febrero de 2021).

${ }^{74}$ Letícia Lima Borges, et al., "Military Nursing in Operation Return to Brazil: Aeromedical Evacuation in the Coronavirus Pandemic", Revista Brasileira de Enfermagem, vol. 73, supl. 2, 2020, e2020029; Pedro Vilela, "Base Aérea de Anápolis está pronta para receber repatriados", Agência Brasil, 7 de febrero de 2020, https:/ / agenciabrasil.ebc.com.br/politica/noticia/20 20-02/base-aerea-de-anapolis-esta-pronta-para-receber-repatriados (consulta del 3 de febrero de 2021).

75 Luiz Henrique Mandetta, op. cit., p. 43.

76 Juliana Arreguy, "Após 4 meses como interino general pazuello assume ministério da saúde”, UOL, 16 de septiembre de 2020, https://noticias.uol.com.br/saude/ultimas-noticias/redacao/2020/09/16/apos4-meses-como-interino-general-pazuello-assume-ministerio-da-saude.htm (consulta del 3 de febrero de 2021).

77 Natalia André, "Pazuello diz que, antes de cargo no governo, não sabia o que era o sus", CNN, 7 de octubre de 2020, https:/ /www.cnnbrasil. 
leño, a nivel federal, se había visto tan alejado de la expertise en salud pública, lo que daña las políticas públicas en este sector a corto, mediano y largo plazo.

Militarizado, el Ministerio de Salud ha promovido activamente la desvalorización o el desmantelamiento de los programas que podrían ser puntos fuertes de la respuesta a la pandemia, como la atención primaria y la vigilancia. Esta estrategia coincide también con los ataques sin precedentes a las instituciones científicas y a las y los científicos brasileños, que amenazan el futuro del sistema de formación, especialmente de posgrado e investigación, que ha hecho posible el volumen y la excelencia de las y los expertos brasileños. Además, el conflicto constante, tanto entre el gobierno federal y los demás poderes de la República, como entre el nivel federal y los gobiernos locales, ha producido un impacto significativo sobre el sistema de salud, cuya estructura federativa está organizada en red. Como resultado de este enfrentamiento, ocurrió una vertiginosa aceleración del proceso de judicialización de la salud, a través del cual el poder judicial ha sido llevado a arbitrar conflictos entre los actores gubernamentales, lo que profundiza la fragmentación de la respuesta nacional a la pandemia.

La expulsión del cuerpo técnico del Ministerio de la Salud también contribuye en la pretensión del gobierno federal de substituir a Estados Unidos, ahora gobernado por el Partido Demócrata, en el liderazgo de una coalición internacional ultraconservadora. Se trata de la "alianza por la familia”, con ataques coordinados especialmente a los derechos sexuales y reproductivos de las mujeres, y a las cuestiones de género. ${ }^{78}$ El 22 de octubre de 2020, Brasil y Estados Unidos

com.br/politica/2020/10/07/pazuello-diz-que-antes-de-cargo-no-gover no-nao-sabia-o-que-era-o-sus (consulta del 3 de febrero de 2021).

78 Ver, por ejemplo, la participación brasileña en la nota presentada por Estados Unidos en las Naciones Unidas en septiembre de 2019. Alex M. Azar II, "Remarks on Universal Health Coverage", U. N. General Assembly Press, 23 de septiembre de 2019, https://public3.pagefreezer.com/ browse/HHS.gov/31-12-2020T08:51; https://www.hhs.gov/about/lea 
lideraron la elaboración de un documento, titulado "Declaración de Ginebra", firmado por 32 Estados, en su mayoría musulmanes o cristianos ultraconservadores, entre los cuales Brasil y Haití son los únicos representantes de América Latina y el Caribe, para los cuales "nunca habrá un derecho al aborto" y "la familia tradicional está siendo atacada". ${ }^{79}$

$\mathrm{Al}$ canciller brasileño se le considera el principal portavoz en la política exterior del núcleo del gobierno federal designado como "ideológico". Es cierto que viene siendo un agitador más que el máximo diplomático del país, pues su discurso antiglobalista nunca proporcionó recompensa tangible, sino al contrario: por ejemplo, a Brasil se le ha impedido participar en importantes foros mundiales, incluso sobre el desarrollo de las vacunas contra la Covid-19.80 "Es bueno ser un paria”, dijo en un discurso en el que atacó a las Naciones Unidas y al multilateralismo en octubre de $2020 .{ }^{81} \mathrm{Su}$ intención es trivializar la constante referencia a Brasil como un paria internacional. ${ }^{82}$ Sin embargo, el núcleo ideológico del

dership/secretary/speeches/2019-speeches/us-government-statementun-universal-health-coverage.html (consulta del 5 de febrero de 2021).

79 Jamil Chade, "Brasil, EUA e ditaduras se aliam: 'jamais haverá direito ao aborto'”, UoL, 22 de octubre de 2020, https://noticias.uol.com.br/ colunas/jamil-chade/2020/10/22/brasil-eua-e-ditaduras-se-aliam-jamais -havera-direito-ao-aborto.htm (consulta del 5 de febrero de 2021).

${ }^{80}$ Dawisson Belém Lopes, "Brazil and Covid-19: A Cautionary Tale", en Shoba Suri (ed.), Rebooting the World: Six Months of Covid-19, Observer Research Foundation, 2020, pp. 13-17, https://www.orfonline.org/wp-co ntent/uploads/2020/09/ORF_Monograph_RebootingTheWorld.pdf (consulta del 2 de febrero de 2021).

${ }^{81}$ Ministerio de Relaciones Exteriores, "Discurso do Ministro das Relações Exteriores, Ernesto Araújo, na formatura da Turma João Cabral de Melo Neto (2019-2020) do Instituto Rio Branco”, 22 de octubre de 2020, http:/ / antigo.itamaraty.gov.br/pt-BR/discursos-artigos-e-entrevistas-categoria/ministro-das-relacoes-exteriores-discursos/21888-discurso-do-ministro-das-relacoes-exteriores-ernesto-araujo-na-formatura-da-turma-joao-ca bral-de-melo-neto-2019-2020-do-instituto-rio-branco-brasilia-22-de-outu bro-de-2020 (consulta del 4 de febrero de 2021).

${ }^{82}$ Catherine Osborn, "Bolsonaro Made Brazil a Pandemic Pariah - Can Local Leaders Restore the Country's Reputation for Health Leadership?”, 
gobierno encuentra resistencias de sectores que propugnan por el pragmatismo diplomático, especialmente parte de los militares y ruralistas ${ }^{83}$ que, en cierta medida, podrían ver afectados sus intereses por acciones pautadas por la ideología. ${ }^{84}$

\section{Consideraciones finales}

Ante la Covid-19, el papel de la oms en 2020 confirma la narrativa científico-humanitaria sobre el nuevo coronavirus, tanto en lo que respecta a la elaboración de las políticas sanitarias nacionales como a las expectativas mundiales sobre los procesos de contagio, la vigilancia epidemiológica y las opciones de contención de la enfermedad. ${ }^{85} \mathrm{Al}$ oponerse a la oms, Brasil está cerrando la puerta a la redefinición del campo de la salud global en el periodo posemergencia, incluso al debate sobre la reforma de esta organización. El mundo en desarrollo pierde a uno de sus principales líderes, comprometiendo las posibilidades de que surja una correlación de fuerzas más favorable a los intereses del Sur global en varios temas.

A nivel regional, a su vez, Brasil no está aprovechando el legado de la Unasur, que podría garantizar una cooperación capaz de contribuir eficazmente a la lucha contra la pandemia. ${ }^{86}$ Las dos renuncias, multilateral y regional, se derivan

Foreign Affairs, 7 de julio de 2020, https:/ /www.foreignaffairs.com/articles/ brazil/2020-07-07/bolsonaro-made-brazil-pandemic-pariah (consulta del 5 de febrero de 2021).

${ }^{83}$ Ruralistas se denomina a quienes representan y defienden los intereses de los productores agropecuarios.

${ }^{84}$ Miriam Gomes Saraiva y Álvaro Vicente Costa Silva, "Ideologia e pragmatismo na política externa de Jair Bolsonaro", Relações Internacionais, núm. 64, 2019, pp. 117-137.

${ }^{85}$ Bernabé Malacalza y Mónica Hirst, “¿Podrá reinventarse el multilateralismo? El orden internacional y el coronavirus”, Revista Nueva Sociedad, núm. 287, 2020, pp. 35-48.

${ }^{86}$ Paulo Marchiori Buss y Sebastián Tobar, "Covid-19 e as oportunidades de cooperação internacional em saúde”, Cadernos de Saúde Pública, vol. 36, núm. 4, 2020, e00066920. 
de la misma raíz: la ausencia de voluntad de contener la propagación de la enfermedad. Para que la epidemia se extienda rápidamente, es esencial hacer frente a las pruebas científicas, que son la base principal e inalienable de la acción de la oms. El proceso de militarización del Ministerio de Salud correspondió al sometimiento ideológico de una institución estatal tradicional brasileña, cuyas políticas públicas han dejado de orientarse por la expertise y la ciencia.

Debilitada por la estrategia presidencial, una parte importante de los gobiernos locales encontró en la oms, como portavoz de las buenas prácticas científicas, una importante fuente de legitimidad para la adopción de medidas de alto costo político y económico. El sus evitó que la catástrofe empeorara, catalizando la resistencia local a través de sus principios, su tradición de trabajo en red y su estructura federativa. Sin embargo, la expertise de su programa de vacunación todavía no se ha aprovechado y Brasil sigue un paso atrás en la inmunización de su población. Asimismo, la oMs ha orientado a importantes sectores de la prensa brasileña que, ante la omisión del gobierno federal, han desempeñado un papel fundamental en la estrategia de comunicación de riesgos durante la emergencia.

Así, en un pasado reciente, protagonista de una visión crítica de la salud global, Brasil se ha convertido primero en miembro subalterno y, después, presunto líder de una alianza ultraconservadora, guiada por el dogmatismo religioso y la doctrina antiglobalista, orgullosamente convertido en un paria internacional. Este giro, que ha costado más de 240000 muertes en gran parte evitables a nivel nacional, también hipoteca el futuro del Estado brasileño en el escenario internacional.

Finalmente, el gobierno federal brasileño formula en su discurso, y obedece en su práctica, a una jerarquía entre intereses económicos y la protección de la vida, con impacto desproporcional sobre aquéllos a quienes no es permitido dejar de trabajar y de circular, y sobre las personas más vulnerables a la enfermedad. En noviembre de 2020, ya con casi 170000 
muertos, Jair Bolsonaro afirmó: "Todos nosotros vamos a morir un día, aquí todos van a morir. No sirve para nada huir de eso, huir de la realidad. Tienen que dejar de ser un país de maricas". ${ }^{87}$ Por lo tanto, valientes son aquellos que anticipan su propia muerte, en general por asfixia, sacrificados en el altar de la continuidad de la actividad económica. Así, nos parece importante aclarar que, en el caso de Brasil, el neoliberalismo epidemiológico no se manifiesta como negligencia o como una sucesión de omisiones gubernamentales que hubiera llevado la pandemia a seguir su curso natural. Al contrario, es una decisión del gobierno federal la de promover activamente el contagio masivo gracias a la exacerbación del ideario neoliberal y a los recursos discursivos del populismo conservador, pese a la resistencia de diversos actores nacionales y al repudio internacional. Al hacerlo, suponiendo que las autoridades federales brasileñas logren implementar esta estrategia con total impunidad, las pandemias se convertirán en un poderoso instrumento de exterminio de poblaciones vulnerables, a disposición de futuros gobiernos. Teniendo en cuenta que los intervalos entre las pandemias tienden a ser cada vez más cortos, se puede deducir que el neoliberalismo aplicado a la salud, en alianza con el populismo de extrema derecha, habrá alcanzado en el caso brasileño una de las expresiones más importantes y aterradoras de su evolución histórica.

\section{REFERENCIAS BIBLIOGRÁFICAS}

Аввasi, Kamran, "Covid-19: Social Murder, They Wrote-Elected, Unaccountable, and Unrepentant”, $B M J$, versión en línea, 3 de febrero de 2021, 372:n314 https://doi.org/10.1136/bmj.n314 (consulta del 4 de febrero de 2021).

87 "Jair Bolsonaro sobre Covid-19: 'tienen que dejar de ser un país de maricas"”, $D W, 11$ de noviembre de 2020, https://www.dw.com/es/jair-bol sonaro-sobre-covid-19-tienen-que-dejar-de-ser-un-pa \% C3\%ADs-de-mari cas/a-55559816 (consulta del 5 de febrero de 2021). 
Aguilar Perez, Fernanda, "A Brazilian Health Foreign Policy? The Role of Health in Brazilian Foreign Affairs", tesis de doctorado, Relaciones Internacionales, São Paulo, Instituto de Relações Internacionais-Universidade de São Paulo/King's College London, 2018.

Almeida, Celia, "Política externa e cooperação internacional no Brasil: eixos estratégicos e agendas", en Paulo Marchiori Buss y Sebastián Tobar (coords.), Diplomacia da saúde e saúde global: perspectivas latino-americanas, Río de Janeiro, Editora Fiocruz, 2017, pp. 41-86.

Almeida-Filho, Naomar, "Pandemia de Covid-19 no Brasil: equívocos estratégicos induzidos por retórica negacionista”, en Principais elementos, Brasilia, Conselho Nacional de Secretários de Saúde, 2021, pp. 214-225, http:/ / www.rets.epsjv.fiocruz.br/si tes/default/files/arquivos/biblioteca/covid-19-volume1.pdf (consulta del 6 de febrero de 2021).

Alvarenga, Alexandre Andrade, et al., "Desafios do estado brasileiro frente à pandemia pela covid-19: o caso da paradiplomacia maranhense", Cadernos de. Saúde Pública, vol. 36, núm. 12, 2020, e00155720.

André, Natalia, "Pazuello diz que, antes de cargo no governo, não sabia o que era o sus", CNN, 7 de octubre de 2020, https://www. cnnbrasil.com.br/politica/2020/10/07/pazuello-diz-que-an tes-de-cargo-no-governo-nao-sabia-o-que-era-o-sus (consulta del 3 de febrero de 2021).

ARAújo, Ernesto, "Chegou o comunavírus", Metapolítica 17, 22 de abril de 2020, https:/ / www.metapoliticabrasil.com/post/chego u-o-comunav\%C3\%ADrus (consulta del 3 de febrero de 2021).

Arreguy, Juliana, “Após 4 meses como interino general pazuello assume ministério da saúde", UOL, 16 de septiembre de 2020, https://noticias.uol.com.br/saude/ultimas-noticias/redacao/2020/09/16/apos-4-meses-como-interino-general -pazuello-assume-ministerio-da-saude.htm (consulta del 3 de febrero de 2021).

Azar II, Alex M., "Remarks on Universal Health Coverage", U.N. General Assembly Press, 23 de septiembre de 2019, https://pu blic3.pagefreezer.com/browse/HHS.gov/31-12-2020T08:51/ 
FI LXI-2 Brasil laboratorio del “NEOliberalismo EPIDEMiolóGico” 459

https://www.hhs.gov/about/leadership/secretary/speeches/ 2019-speeches/us-government-statement-un-universal-healthcoverage.html (consulta del 5 de febrero de 2021).

Barbosa, Allan, et al., "Programa Mais Médicos: como avaliar o impacto de uma abordagem inovadora para superação de iniquidades em recursos humanos", Revista Panamericana de Salud Pública, vol. 42, núm. 185, 2018, pp. 1-8.

Benites, Afonso y Naira Galarraga Gortázar, "Mandetta, o conservador que vestiu o colete do sus e entrincheirou Bolsonaro", El Pais, 5 de abril de 2020, https://brasil.elpais.com/ brasil/2020-04-04/mandetta-o-conservador-que-vestiu-o-cole te-do-sus-e-entrincheirou-bolsonaro.html (consulta del 3 de febrero de 2021).

Biehl, João y Adriana Petryna, When People Come First: Critical Studies in Global Health, Princeton, University Press, 2013.

BieHL, João, "Theorizing Global Health", MAT: Medicine Anthropology Theory, vol. 3, núm. 2, 2016, pp. 127-142.

BirN, Anne-Emanuelle, “¿Politizándolo o puliéndolo? Subsanar las desigualdades en una generación: alcanzar la equidad sanitaria actuando sobre los determinantes sociales de la salud", Medicina Social, vol. 4, núm. 3, 2009, pp. 189-207.

Borges, Letícia, et al., "Military Nursing in 'Operation Return to Brazil': Aeromedical Evacuation in the Coronavirus Pandemic", Revista Brasileira de Enfermagem, vol. 73, supl. 2, 2020, e2020029.

Brown, Theodore, Marcos Cueto y Elizabeth Fee, "A transição de saúde pública 'internacional' para 'global' e a Organização Mundial da Saúde", História, Ciências, Saúde-Manguinhos, vol. 13, núm. 3, 2006, pp. 623-647.

Buss, Paulo y Sebastián Tobar, "COVID-19 e as oportunidades de cooperação internacional em saúde”, Cadernos de Saúde Pública, vol. 36, núm. 4, 2020, e00066920.

Buss, Paulo, "Brazilian International Cooperation in Health in the Era of SUS”, Ciência Ẽ Saúde Coletiva, vol. 23, núm. 6, 2018, pp. 1881-1890.

Carmo, Eduardo Hage, Gerson Penna y Wanderson Kleber de Oliveira, "Emergências de saúde pública: conceito, caracte- 
rização, preparação e resposta”, Estudos avançados, vol. 22, núm. 64, 2008, pp. 19-32.

Carvalho, Priscila, "sus pago? Entenda falas 'polêmicas' do ministro da Saúde em programa da Tv Cultura”, UOL, 28 de mayo de 2019, https://www.uol.com.br/vivabem/noticias/redacao/ 2019/05/28/sus-pago-entenda-falas-do-ministro-da-saude-em -programa-da-tv-cultura.htm (consulta del 3 de febrero de 2021). Castro, Marcia et al., "Brazil's Unified Health System: The First 30 Years and Prospects for the Future", The Lancet, núm. 10195, 2019, pp. 345-356.

Chade, Jamil, "Brasil, EuA e ditaduras se aliam: 'jamais haverá direito ao aborto'", UOL, 22 de octubre de 2020, https://noticias.uol. com.br/colunas/jamil-chade/2020/10/22/brasil-eua-e-ditadu ras-se-aliam-jamais-havera-direito-ao-aborto.htm (consulta del 5 de febrero de 2021).

Chade, Jamil, "Brasil deve R \$ 169 milhões para oms; Dívida é quarta maior da agência”, UOL, 8 de abril de 2020, https://noticias. uol.com.br/colunas/jamil-chade/2020/04/08/brasil-deve-r169-milhoes-para-oms-divida-e-quarta-maior-da-agencia.ht m\#: :text=Brasil \% 20deve \% 20R\% 24\% 20169\% 20milh\%C3\%B5es, \% 2F04\% 2F2020\%20\%2D\%20UOL\%20Not\%C3\%ADcias (consulta del 3 de febrero de 2021).

Comisión Interamericana de Derechos Humanos (CIDH), "Membros dos Povos Indígenas Yanomami e Ye'kwana em relação ao Brasil”, Resolución 35/2020, 17 de julio de 2020.

Comité Científico de Combate al Coronavirus del Consórcio Nordeste, "Comitê científico de combate ao Coronavírus", 2020, https://www.comitecientifico-ne.com.br/ (consulta del 3 de febrero de 2021).

Costa, Maria da Conceição Nascimento, et al., "Mortalidade infantil no Brasil em períodos recentes de crise econômica", Revista de Saúde Pública, vol. 37, núm. 6, 2003, pp. 699-706.

"Covid-19 in Brazil: 'So What?'”, Editorial, The Lancet, núm. 10235, 9 de mayo de 2020, p. 1461.

Cristina, Paula, "Ainda bem que temos o SUS", Isto é Dinheiro, 28 de febrero de 2020, https://www.istoedinheiro.com.br/ain da-bem-que-temos-o-sus / (consulta del 3 de febrero de 2021). 
FI LXI-2 Brasil laboratorio del “NEOliberalismo EPIDEMiolóGico” 461

Croda, Julio, et al., "COVID-19 in Brazil: Advantages of a Socialized Unified Health System and Preparation to Contain Cases", Revista da Sociedade Brasileira de Medicina Tropical, vol. 53, 17 de abril de 2020, e20200167.

Croda, Julio Henrique Rosa y Leila Posenato Garcia, "Immediate Health Surveillance Response to COVID-19 Epidemic", Epidemiologia e Serviços de Saúde, vol. 29, núm. 1, 2020 , e2020002.

Cueto, Marcos, Theodore Brown y Elizabeth FeE, The World Health Organization. A History, Cambridge, University Press, 2019.

Cueto, Marcos, "El legado de Alma-Ata, 40 años después", Trabalho, educação e saúde, vol. 16, núm. 3, 2018, pp. 845-848.

Della Coletta, Ricardo, Bernardo Karam y Gustavo Uribe, "É guerra, tem que jogar pesado com governadores, diz Bolsonaro a empresários", Folha de S. Paulo, 14 de mayo de 2020, https:/ / www1.folha.uol.com.br/poder/2020/05/e-guerra-tem-que-jo gar-pesado-com-governadores-diz-bolsonaro-a-empresarios. shtml (consulta del 5 de febrero de 2021).

Esteves, Paulo, et al., "A rede de políticas de saúde pública e a cooperação Sul-Sul: os casos de Moçambique e Angola", Lua Nova, núm. 98, 2016, pp. 199-230.

Fuerza Aérea Brasileña, "Operação Regresso à Pátria Amada Brasil”, 2020, https://www.fab.mil.br/operacaoregresso/ (consulta del 3 de febrero de 2021).

FreIre, Vinicius, "Fiocruz e OPAS promovem capacitação para diagnóstico do novo coronavírus", Portal Fiocruz, 3 de febrero de 2020, https://portal.fiocruz.br/noticia/fiocruz-e-opas-pro movem-capacitacao-para-diagnostico-do-novo-coronavirus (consulta del 5 de febrero de 2021).

FrEY, Isabel, “Herd Immunity' is Epidemiological Neoliberalism”, The Quarantines, 19 de marzo de 2020, https:/ / thequarantimes. wordpress.com/2020/03/19/herd-immunity-is-epidemiological-neoliberalism/ (consulta del 5 de febrero de 2021).

Henriques, Cláudio Maierovitch Pessanha y Wagner VasconceLOS, "Crises dentro da crise: respostas, incertezas e desencontros no combate à pandemia da Covid-19 no Brasil", Estudos avançados, vol. 34, núm. 99, 2020, pp. 25-44. 
Herrero, María Belén y Diana Tussie, "UNASUR Health: A Quiet Revolution in Health Diplomacy in South America”, Global Social Policy, vol. 15, núm. 3, 2015, pp. 261-277.

Kaddar, Miloud, Julie Milstien y Sarah Schmitt, "Impact of BRICS' Investment in Vaccine Development on the Global Vaccine Market”, Boletín de la OMS, vol. 92, núm. 6, 2014, pp. 385-446.

"Jair Bolsonaro sobre COVID-19: 'tienen que dejar de ser un país de maricas"”, $D W, 11$ de noviembre de 2020, https://www.dw.com/ es/jair-bolsonaro-sobre-covid-19-tienen-que-dejar-de-ser-unpa\% C3\%ADs-de-maricas/a-55559816 (consulta del 5 de febrero de 2021).

Lima, Nísia Trinidade, Paulo Marchiori Buss y Rômulo Paes-SouSA, "A pandemia de COVID-19: uma crise sanitária e humanitária”, Cadernos de Saúde Pública, vol. 36, núm. 7, 2020, pp. 1-4.

Lopes, Dawisson Belém, "Brazil and COVID-19: A Cautionary Tale", en Shoba Suri (ed.), Rebooting the World: Six Months of Covid-19, Observer Research Foundation, 2020, pp. 13-17, https://www. orfonline.org/wp-content/uploads/2020/09/ORF_Monogra ph_RebootingTheWorld.pdf (consulta del 2 de febrero de 2021).

Lowy Institute, "Covid Performance Index", https://interactives. lowyinstitute.org/features/covid-performance/\#rankings (consulta del 5 de febrero de 2021).

MACIEL, Victor, "OMS e diretores recebem homenagem do Governo Federal ", Ministerio de la Salud, 21 de marzço de 2018, https:/ / www.saude.gov.br/noticias/agencia-saude/42856-oms-e-direto res-recebem-homenagem-do-governo-federal (consulta del $3 \mathrm{fe}-$ brero de 2021).

Malacalza, Bernabé y Mónica Hirst, “¿Podrá reinventarse el multilateralismo? El orden internacional y el coronavirus", Revista Nueva Sociedad, núm. 287, 2020, pp. 35-48.

Mandetta, Luiz Henrique, Um paciente chamado Brasil, Río de Janeiro, Objetiva, 2020.

McKee, Martin, et al., "Are Populist Leaders Creating the Conditions for the Spread of Covid-19?”, International Journal of Health Policy and Management, versión en línea, 2020, pmid:32668893, 
FI LXI-2 Brasil laboratorio del “NEOliberalismo EPIDEMiolóGico” 463

doi:10.34172/ijhpm.2020.124 (consulta del 5 de febrero de 2021).

Ministerio de la Salud, "Painel Coronavírus", 2020, https:/ /covid. saude.gov.br/ (consulta del 20 de febrero de 2021).

Ministerio de la Salud, "Plano Nacional de Operacionalização da Vacinação contra a Covid-19", $1^{\text {ra }}$ versión, 16 de diciembre de 2020, https://www.gov.br/saude/pt-br/media/pdf/2020/de zembro/16/plano_vacinacao_versao_eletronica-1.pdf (consulta del 20 de diciembre de 2020.

Ministerio de Relaciones Exteriores, "Discurso do Ministro das Relações Exteriores, Ernersto Araújo, na formatura da Turma João Cabral de Melo Neto (2019-2020) do Instituto Rio Branco", Brasilia, 22 de octubre de 2020, http:/ /www.itamaraty.gov.br/pt-BR / discursos-artigos-e-entrevistas-categoria/ministro-das-relaco es-exteriores-discursos/21888-discurso-do-ministro-das-relacoes -exteriores-ernesto-araujo-na-formatura-da-turma-joao-cabralde-melo-neto-2019-2020-do-instituto-rio-branco-brasilia-22-deoutubro-de-2020 (consulta del 4 de febrero de 2021).

Ministerio de Relaciones Exteriores, "Participação do ministro Ernesto Araújo na 34 a Reunião do Conselho de Governo", 9 de junio de 2020, http:/ / www.itamaraty.gov.br/pt-BR/discur sos-artigos-e-entrevistas-categoria/ministro-das-relacoes-exter iores-discursos/21561-participacao-do-ministro-ernesto-araujona-34-reuniao-do-conselho-de-governo-9-de-junho-de-2020 (consulta del 3 de febrero de 2021).

Ministerio de Relaciones Exteriores, "Declaração Presidencial sobre a Renovação e o Fortalecimento da Integração da América do Sul”, 22 de marzo de 2019, http://www.itamaraty.gov.br/ pt-BR/notas-a-imprensa/20203-declaracao-presidencial-so bre-a-renovacao-e-o-fortalecimento-da-integracao-da-americado-sul (consulta del 3 de febrero de 2021).

Ministerio de Relaciones Exteriores, "Declaração presidencial do PROSUL sobre ações conjuntas para enfrentar a pandemia do coronavírus", 18 de marzo de 2020, http://www.itamaraty. gov.br/pt-BR/notas-a-imprensa/21460-declaracao-presiden cial-do-prosul-sobre-acoes-conjuntas-para-enfrentar-a-pande mia-do-coronavirus-2 (consulta del 3 de febrero de 2020. 
Ministerio de Relaciones Exteriores/Ministerio de Defensa, "Nota Conjunta do Ministério de Relações Exteriores e Ministério da Defesa", 8 de febrero de 2020, http://www.itamaraty.gov.br/ pt-BR/notas-a-imprensa/21299-nota-conjunta-do-ministeriodas-relacoes-exteriores-e-do-ministerio-da-defesa (consulta del 3 de febrero de 2021).

Molina, Joaquín, Renato Tasca y Julio SuÁrez, "Monitoring and Evaluation of the PAHO/WHO Cooperation Project, the Mais Médicos (More Doctors) Program: A Mid-Term Assessment", Ciência. Ẽ Saúde Coletiva, vol. 21, núm. 9, 2016, pp. 2925-2933. Nuclear Threat Initiative/The Johns Hopkins Center for Health Security, Global Health Security Index. Building Collective Action and Accountability, 2019, https://www.ghsindex.org/wp-content/ uploads / 2019/10/2019-Global-Health-Security-Index.pdf (consulta del 5 de febrero de 2021).

Nunes, João, "The Covid-19 Pandemic: Securitization, Neoliberal Crisis, and Global Vulnerabilization", Cadernos de Saúde Pública, vol. 36, núm. 5, 2020, e00063120.

Oficina de Asuntos Internacionales de la Salud, Saludy Política Externa: los 20 años de la Oficina de Asuntos Internacionales de Salud (1998-2018), Brasilia, Ministerio de Salud, 2018, http://bvsms. saude.gov.br/bvs/publicacoes /salud_politica_externa_20 anos_espanhol.pdf (consulta del 5 de febrero de 2021).

Organización Mundial de la Salud (oms), "WHO Coronavirus Disease (Covid-19) Dashboard”, 2021, https://covid19.who.int/ (consulta del 4 de febrero de 2021).

Organización Mundial de la Salud (oms), "Inmunidad colectiva, confinamentos y Covid-19”, 31 de diciembre de 2020, https:// www.who.int/es/news-room/q-a-detail/herd-immunity-lock downs-and-covid-19 (consulta del 5 de febrero de 2021).

Organización Mundial de la Salud (oms), "Alocución de apertura del Director General de la OMS en la conferencia de prensa sobre la COVID-19 del 12 de octubre de 2020", 12 de octubre de 2020, https://www.who.int/es/director-general/speeches/deta il/who-director-general-s-opening-remarks-at-the-media-briefing-on-covid-19-12-october-2020 (consulta del 4 de febrero de 2021). 
FI LXI-2 Brasil laboratorio del “NEOliberalismo EPIDEMiolóGico” 465

Organización Mundial de la Salud (oms), "Rio Political Declaration on Social Determinants of Health", World Conference on Social Determinants of Health, Rio de Janeiro, 2011.

Organización Pan-Americana de Salud (ops), "Folha informativa COVID-19 - Escritorio da OPAS e da OMS no Brasil", 2020, https://www.paho.org/pt/covid19 (consulta del 15 de enero de 2021).

Ortega Francisco y Michael Orsini, "Governing COVID-19 without Government in Brazil: Ignorance, Neoliberal Authoritarianism, and the Collapse of Public Health Leadership", Global Public Health, vol.15, núm. 9, 2020, pp. 1257-1277.

Osborn, Catherine, "Bolsonaro Made Brazil a Pandemic Pariah. Can Local Leaders Restore the Country's Reputation for Health Leadership?", Foreign Affairs, 7 de julio de 2020, https://www. foreignaffairs.com/articles/brazil/2020-07-07/bolsonaro-ma de-brazil-pandemic-pariah (consulta del 5 de febrero de 2021).

Riggirozzi, Pía, "Coronavirus y el desafío para la gobernanza regional en América Latina”, Análisis núm. 12, Fundación Carolina, 2020.

Saraiva, Miriam Gomes y Álvaro Vicente Costa Silva, "Ideologia e pragmatismo na política externa de Jair Bolsonaro", Relações Internacionais, núm. 64, 2019, pp. 117-137.

Scheffer, David, "Is It a Crime to Mishandle a Public Health Response?”, Council on Foreign Affairs, 22 de abril de 2020, https:/ / www.cfr.org/article/it-crime-mishandle-public-health-respon se (consulta del 5 de febrero de 2021).

Secretaría de Vigilancia en Salud, svs, Zika Virus in Brazil: The sus Response, Ministerio de la Salud, 2017, http://www.saude.gov. br/images/pdf/2017/setembro/21/zika-virus-in-brazil-2017. pdf (consulta del 3 de febrero de 2021).

Secretaría de Vigilancia en Salud, svs, Vigilância em saúde: ações inovadoras e resultados: gestão 2011-2014, Brasilia, Ministerio de la Salud, 2015.

Silva, Luiz Antônio Teixeira da, Carlos Henrique Assunção PaIva y Vanessa Nolasco Ferreira, "The World Health Organization Framework Convention on Tobacco Control in the Brazilian Po- 
litical Agenda, 2003-2005”, Cadernos de Saúde Pública, vol. 33, suppl. 3, 2017, e00121016.

SoAREs, Jussara, "Mandetta vê crescer seu capital político e até 'colete' colabora com popularidade”, Terra, 4 de abril de 2020, https://www.terra.com.br/noticias/coronavirus/mandettave-crescer-seu-capital-politico-e-ate-colete-colabora-com-popu laridade,9391bb411915768395644290bbc58c03i5g6bs1t.html (consulta del 3 de febrero de 2021).

Souza, Diego de Oliveira, "A militarização do Ministério da Saúde no Brasil”, Revista Uruguaya de Ciencia Política, vol. 29, núm. 2, 2020, pp. 33-54.

Spautz, Dagmara, "Mandetta: 'Cloroquina nunca teve viés de saúde'”, NCS Total, 23 de julio de 2020, https:/ / www.nsctotal.com. $\mathrm{br} /$ colunistas/dagmara-spautz/mandetta-cloroquina-nuncateve-vies-de-saude (consulta del 3 de febrero de 2021).

Stuckler, David y Sanjay Basu, The Body Economic: Why Austerity Kills, Nueva York, Basic Books, 2013.

VAdell, Javier A. y Clarissa Giaccaglia, "El rol de Brasil en el regionalismo latinoamericano: la apuesta por una inserción internacional solitaria y unilateral", Foro Internacional, vol. 60, núm. 3, 2020, pp. 1041-1080.

Ventura, Deisy y Rossana Reis, "An Unprecedented Attack on Human Rights in Brazil: The Timeline of the Federal Government's Strategy to Spread Covid-19”, Bulletin Rights in the Pandemic, núm. 10, Offprint, São Paulo, Cepedisa-usp/Conectas Direitos Humanos, enero de 2021, https://www.conectas.org/wp/wpcontent/uploads/2021/01/10boletimcovid_english_03.pdf (consulta del 6 de febrero de 2021).

Ventura, Deisy, "Public Health and Brazilian Foreign Policy", sur, vol. 10, núm. 19, 2013, pp. 99-119.

Verdélio, Andeia, "Brasil recebe 2 milhões de doses de hidroxicloroquina dos EUA-Países farão testes do medicamento no tratamento da covid-19", Agência Brasil, 1 de junio de 2020, https:/ / agenciabrasil.ebc.com.br/politica/noticia/2020-06/brasil-re cebe-dois-milhoes-de-doses-de-hidroxicloroquina-dos-eua (consulta del 3 de febrero de 2021). 
FI LXI-2 Brasil laboratorio del “NEOliberalismo EPIDEMiolóGico” 467

Vilela, Pedro, "Base Aérea de Anápolis está pronta para receber repatriados", Agência Brasil, 7 de febrero de 2020, https:/ /agen ciabrasil.ebc.com.br/politica/noticia/2020-02/base-aerea-de -anapolis-esta-pronta-para-receber-repatriados (consulta del 3 de febrero de 2021).

Vilela, Pedro, "Bolsonaro diz que Brasil pode sair da oms", Agência Brasil, 5 de junio de 2020, https://agenciabrasil.ebc.com. $\mathrm{br} /$ politica/noticia/2020-06/bolsonaro-diz-que-brasil-podesair-da-oms (consulta del 3 de febrero de 2021).

Yamey, Gavin y Gregg Gonsalves, "Donald Trump: A Political Determinant of Covid-19”, BMJ, núm. 369, 2020, m1643, https:// www.bmj.com/content/369/bmj.m1643 (consulta del 3 de febrero de 2021). 
